\title{
The modified mortality decomposition model and its application in the China longevity risk analysis
}

\author{
Zhang Ning \\ China Institute For Actuarial Science \\ Central University of Finance and Economics, Beijing, China \\ nzhang@amss.ac.cn
}

\begin{abstract}
- the paper made an adjustment on the mortality decomposition model which was first proposed by the author. The mortality data can be processed by the classical wavelet and HHT methods. Compared with the classical mortality analyzing method, more information about longevity risk can be captured by the adjusted mortality decomposition. As a new development, the adjusted mortality decomposition is more effective for the short data set like China. Also the paper gave a modified form of longevity risk index which is different from that the author introduced in another paper. The new modified index is more suitable for China. Based on the adjusted decomposition of mortality rate data and modified longevity risk index, the paper gave their application and detailed analysis on China longevity risk. The important result of different provinces is also given.
\end{abstract}

longevity risk; mortality decomposition model; longevity risk index; stable distribution

\section{INTRODUCTION}

Mortality data play the key role in the research of longevity risk. So many researchers paid more attention to mortality data analysis and promoted many models. They use some models to describe and predict the future mortality rate about some fixed group.

As we know, the most popular method is life table. For a country, the basic model of the population mortality rate is whole national life table. And an insurance company also constructs life table based on its collection of products data. It makes sense that there is some difference between the above two. Another way to model mortality is to find the laws for the force of mortality. The mortality force is defined as the following:There are many laws for the mortality force like Gompertz law, Makebam law, Tbiele law and Weibull law.

Now, Lee-Carter model became the basis for getting the information from mortality data set. And many derivative models followed it and were proved effective in different directions. But limited to the model framework, the information seeking stumbled. Just for that, the mortality decomposition was proposed by the author [1] and we will discuss it in the section 2.

Further, it is very helpful for an insurance company or other financial company to give a longevity risk index which shows the level of longevity risk of products. Many managers in insurance companies must face many products whose profits are influenced by longevity. It is possible that every product is designed for some specific people group and the longevity risk should be different. Always, only the way the national mortality rate table is used for all groups will bring the wrong result. And based on the past products data, the company can compute the mortality table for every group. So is there a good way to utilize the data to give a longevity risk index for the managers?

Also, it is important to show a country the index of longevity risk since many countries must be involved with aging society. Different department is concerned with different group. For example, the social security pays more attention to the whole nation people and the medical department will pay more attention to the group with illness. So is there a longevity risk index for the whole nation?

In the former paper, the author introduced the longevity risk index, it satisfied the followings conditions: 1) It can use a simple index show the longevity risk of the fixed group; 2) The different indexes are express the difference the longevity risk faced by different group; 3) It is normalized process to compute it.

In this paper, Section II is the most important one. We first introduce the basic tools and theory for the mortality decomposition in it. The modified longevity risk computation also was developed in it. In section III, we will use the mortality data from American and China to compute longevity risk model and naturally we give the longevity risk index of different provinces. And the conclusion is given in Section IV.

\section{ADJUSTED DECOMPOSITON OF MORTALITY RATE AND LONGEVITY INDEX}

Since Lee-Carter model can't get enough information from the data set. So we construct the mortality decomposition based on Lee-Carter model. If we regard the factors as the different signals, then the kernel focus is to decompose into several level signals. The framework can be described by the followings:

$$
\begin{gathered}
\mathrm{M}=\mathrm{L}+\mathrm{H}_{1}+\mathrm{H}_{2}+\epsilon \\
\mathrm{L}=\text { Lee }- \text { Carter Model } \\
\mathrm{H}_{1}, \mathrm{H}_{2} \text { are from EMD of HHT }
\end{gathered}
$$

In fact, HHT can give more levels for decomposition. But in the analysis of mortality data, two levels are enough for the following computation. And the remainder is naturally regarded as the white noise. 
The classical dynamic model for mortality over age and time is Lee-Carter model. The model has the following form:

$$
\operatorname{lnm}_{\mathrm{x}}(\mathrm{t})=\alpha_{\mathrm{x}}+\beta_{\mathrm{x}} \mathrm{k}_{\mathrm{t}}+\epsilon_{\mathrm{x}, \mathrm{t}}
$$

It is impossible to calibrate the Lee-carter model without other constraints. For example, so many researches choose the following constraints:

$$
\sum \mathrm{k}_{\mathrm{t}}=0, \sum \beta_{\mathrm{t}}=1
$$

Other constraints can be adopted. But the constraints have no impact on the fitting and forecasting of the model.

Based on the above, we can calibrate the model and solve the result of parameters. It is proved effective for the normal mortality data set. But for some data set like short data set, the information can't be captured completely and the $\epsilon$ is not the white noise. So we adjusted the mortality decomposition and introduce another powerful tool called independent component analysis ICA. ICA is a special one of blind source separation. The mortality data in period dimension can be treated as the original signal. We use the popular algorithm in the paper [2] which gave the detailed process. As a result, we call this model the adjusted mortality decomposition model.

After that, we will use the results to give the adjusted longevity index computation.

Just like what we have said, mortality data can be decomposed into three level data based on the mortality decomposition model. And every level data plays different important role in the change of mortality. And we use the different weights to change the original data into the new data set.

We choose the weights $\{0.5,0.3,0.2\}$ for three levels. There are two reasons for this weights set: the first reason is the fact that more definite trend should be given more weight; the second reason is that it is from optimization results of function with free weights.

We denote the new mortality data set as $m_{x, t}^{*}$. And define the longevity risk index function as the following map:

$$
f_{\text {index }}:\left\{m_{x, t}^{*}\right\}_{0 \leq x \leq M, 0 \leq t \leq T} \times[0,+\infty] \rightarrow R
$$

is the time horizon for longevity risk index and it is understandable that the longevity risk index of different time horizon should different. Also, we can get that more accurate longevity risk index is for the shorter time horizon.

Here we give two kinds of definition, one of them is the following:

$$
\mathrm{f}_{\text {index } 1}=\mathrm{E}_{\mathrm{x}}\left(\mathrm{E}\left(\max \left\{0, \Delta \mathrm{m}_{\mathrm{x}, \mathrm{t}}^{*}\right\}\right)\right)
$$

The other way is the following:

$$
\mathrm{f}_{\text {index2 }}=\mathrm{E}_{\mathrm{x}}\left(\operatorname{VaR}_{\mathrm{t}}\left(\mathrm{m}_{\mathrm{x}, \mathrm{t}}^{*}\right)\right)
$$

Here $\mathrm{VaR}$ is defined as its definition in financial risk management; VaR method takes the prominent role in the financial risk management. Its essence is to give a explicit idea about the faced risk and use a simple number to express it. For a given confidence level and time horizon, the probability for the portfolio loss to exceed the VaR will be the given confidence level over the given time horizon.

Let $\beta$ is the confidence level like $5 \%$ and $L$ is the loss for portfolio. Then,

$$
\operatorname{VaR}_{\beta}(\mathrm{L})=-\inf \left\{l \in \mathrm{R}: \mathrm{F}_{\mathrm{L}}(\mathrm{l}) \geq \beta\right\}
$$

There are many methods to compute VaR value for portfolio like Delta-Normal method, historical data method and simulation methods. Because the delta-Normal method is limited to the normal distribution, we will use the other methods to computing VaR for mortality rate data.

Now for the first definition, the computing process is the following:

Step 1: Computing $\Delta \mathrm{m}_{\mathrm{x}, \mathrm{t}}^{*}$ for fixed $\mathrm{x}$ age based on the mortality data series; results;

Step 2: Removing the negative results for the computing

Step 3: Computing the expectation;

Step 4: Computing the expectation according to the population proportion and get the result.

Now for the other definition, the computing process is the following:

Step 1: Computing $\operatorname{VaR}_{t}\left(m_{x, t}^{*}\right)$ for fixed $x$ age based on the mortality rate series;

Step 2: Computing the expectation according to the population proportion and get the result.

Here, in the first step, we use the historical data to compute $\Delta \mathrm{m}_{\mathrm{x}, \mathrm{t}}^{*}$ and $\operatorname{VaR}_{\mathrm{t}}\left(\mathrm{m}_{\mathrm{x}, \mathrm{t}}^{*}\right)$. But in fact there are two other methods which can be used for computing: One method is statistical distribution and this method will give the distribution of the mortality rate; the other method is Monte-Carlo simulation. Both methods also must use the historical data. In practices, the results from three methods are similar.

In our practice, the above process of LRI is not suitable for China mortality data. Because of missing data, the computing result seems to enlarge the longevity risk. Some facts also bring conflicts. So how can we get more information and more rational outcome? The key is the distribution.

We observe the fact the data after mortality decomposition model always fit normal distribution very well. But for some short data, like China, the mortality decomposition model can't capture the most effective information. It does not mean that it is not a good method. It means that HHT can't continue to get information in those data sets.

We modified the decomposed result. We use stable distribution or fractal distribution instead of normal distribution. And under the two definitions, we also can give the longevity risk index. It should be called modified longevity risk index (MLRI). 
A random variable $\mathrm{X}$ is called stable if its characteristic function is given by the following:

$$
\begin{gathered}
\mathrm{f}(\mathrm{t}, \mu, \mathrm{c}, \alpha, \beta)=\exp \left(\mathrm{it} \mu-|\mathrm{ct}|^{\alpha}(1-i \beta \operatorname{sgn}(t) \omega(\mathrm{t}, \alpha))\right) \\
\text { Here, } \omega(\mathrm{t}, \alpha)=\left\{\begin{array}{c}
\operatorname{tg}\left(\frac{\alpha \pi}{2}\right) \alpha \neq 1 \\
\left(\frac{2}{\pi}\right) \ln |t| \alpha=1
\end{array}\right. \\
\text { And, } \operatorname{sgn}(\mathrm{t})=\left\{\begin{array}{c}
1, \mu>0 \\
0, \mu=0 \\
-1, \mu<0
\end{array}\right. \text { is a shift parameter. }
\end{gathered}
$$

$\beta \in[-1,1]$ is the skewness parameter which measures the asymmetry of the distribution. $\alpha$ is also the most important parameter which gives the several types of this distribution. In fact, it measure how heavy the distribution's tail is. As we know, both the normal distribution and the Cauchy distribution are the special cases.

We used the stable distribution under the 1st and 2nd definition to compute LRI and get the MLRI of US. The result is the following table (table 1 ). In this table, we also present the LRI as comparison. The table gives the fact that LRI and MLRI are very similar when the data set is long enough.

\begin{tabular}{llllll}
\multicolumn{6}{c}{ Table 1. LRI and MLRI of US } \\
\multicolumn{7}{c}{ US-1st definition US-2nd definition } \\
& \multicolumn{7}{c}{ LRI } & MLRI LRI & MLRI & \\
1 & 0.00476 & 0.004849 & 0.0103 & 0.010405 \\
2 & 0.00572 & 0.006022 & 0.0152 & 0.015746 \\
3 & 0.00622 & 0.006497 & 0.0176 & 0.019181 \\
4 & 0.00644 & 0.006561 & 0.0198 & 0.020765 \\
5 & 0.00671 & 0.007004 & 0.0221 & 0.022345 \\
6 & 0.00689 & 0.006985 & 0.0243 & 0.024766 \\
7 & 0.0071 & 0.007303 & 0.026 & 0.026827
\end{tabular}

\section{LRI AND MLRI RESULTS OF CHINA}

Our Chinese mortality data is a $18 \times 101$ matrix which includes 18 years (1986, 1989, 1994-2009) and 101 ages. The data is from official issued statistical data. And the data is the average result of male and female. The surface formed by the data set is just like showing in Figure 1.

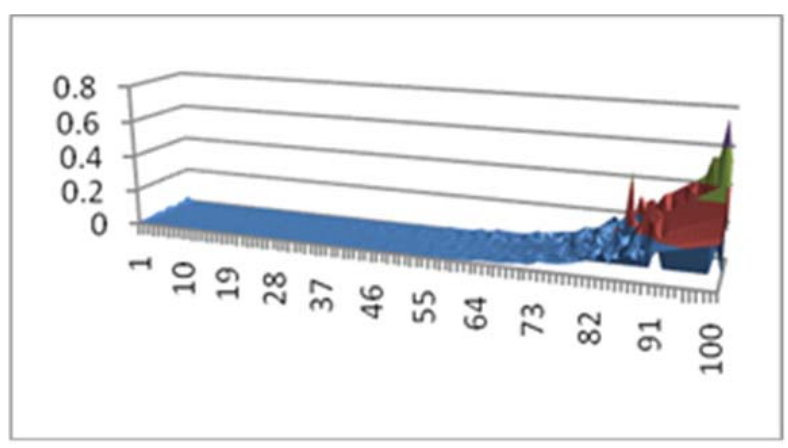

Fig. 1. The surface of China mortality rate (average)
Then the computed final longevity risk index (LRI) is 0.004636 and the modified longevity risk index is 0.002153 . The MLRI is apparently lower than the LRI. The reason is because Chinese data is more different from normal distribution. It can be found from the characteristic parameter.

This is for one year. Considering two years, the computing processing is just like above except the interval time is two year in step 1 . And the result for 2 year is 0.005541 and 0.002618 . And so on. Figure 2 gives the longevity risk index with respect to year. It is understandable that there is more risk for more years.

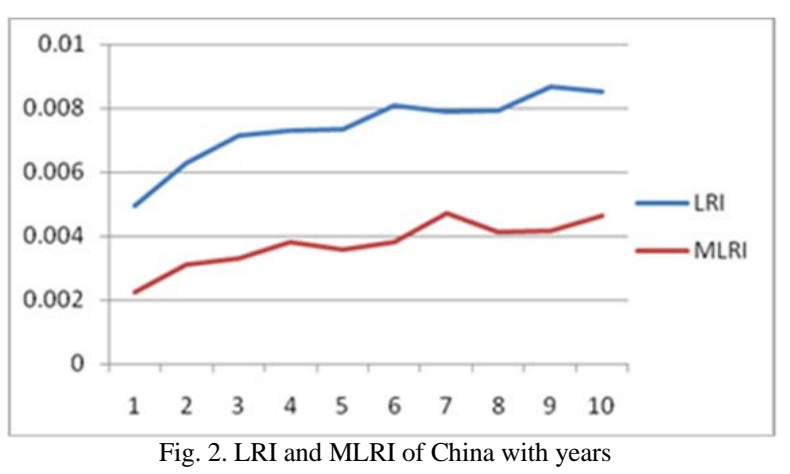

If we use the second definition, the result is similar. The following is the result of LRI and MLRI (Figure 3). Because of VAR, both LRI and MLRI appear with more volatility. It makes sense that more risk will be captured with year. The trend has a special point. The LRI and MLRI do not always increase. If we pay attention to the LRI, the MLRI in 7-year make the most risk! The reason is the short data set. We also computed the MLRI and LRI of many other countries with long data set like US, Australia, there is no similar confusion. VaR computing would fluctuate based on the short historical data set.

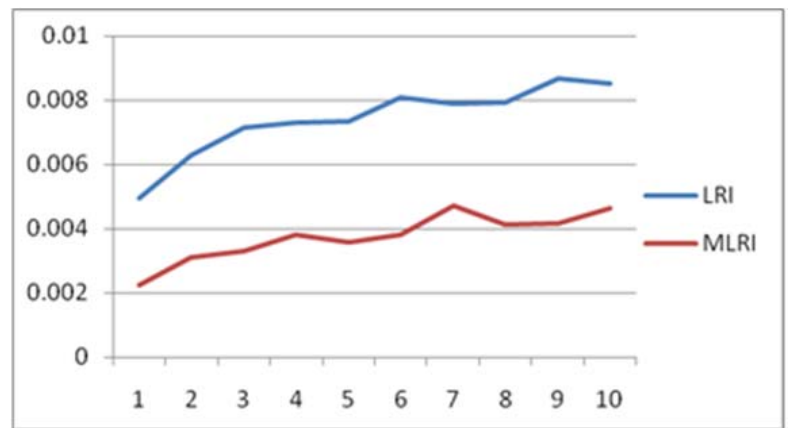

Fig. 3. The trend of American longevity risk with years

Table 2 gives the longevity risk index of some different provinces of China, two and three years. $95 \%$ is the confidence ratio. The data is from the provincial statistical 
data. The results only included some provinces because only a few provinces had the enough data for computing. The data must be more than ten years at least.

From LRI and MRI, Tianjin seems to face the least longevity risk. And Henan seems to face the least longevity risk. Combined with the most population, it is a challenge for Henan to overcome it. From the result, MLRI give more information about longevity risk.

Table 2: LRI and MLRI based on adjusted mortality decomposition model

\begin{tabular}{|c|c|c|c|c|}
\hline \multicolumn{4}{|c|}{ LRI and MLRI of several provinces of China } \\
\hline & 1st Definition & \multicolumn{2}{|c|}{ 2nd Definition } \\
\hline & LRI & MLRI & LRI & MLRI \\
\hline Beijing & 0.00380 & 0.00359 & 0.00412 & 0.00403 \\
\hline Shanghai & 0.00372 & 0.00308 & 0.00312 & 0.00212 \\
\hline Tianjin & 0.00221 & 0.00170 & 0.00233 & 0.00180 \\
\hline $\begin{array}{c}\text { Liaoning } \\
\text { Province* }\end{array}$ & 0.0039 & 0.00333 & 0.00350 & 0.00284 \\
\hline $\begin{array}{c}\text { Zhejiang } \\
\text { Province }\end{array}$ & 0.00376 & 0.00285 & 0.00354 & 0.00332 \\
\hline $\begin{array}{c}\text { Shandong } \\
\text { Province }\end{array}$ & 0.00390 & 0.00373 & 0.004226 & 0.00333 \\
\hline $\begin{array}{c}\text { Jiangsu } \\
\text { Province }\end{array}$ & 0.00372 & 0.0030 & 0.00316 & 0.00219 \\
\hline $\begin{array}{c}\text { Guangdong } \\
\text { Province }\end{array}$ & 0.00353 & 0.00263 & 0.00350 & 0.003321 \\
\hline $\begin{array}{c}\text { Sichuan } \\
\text { Province }\end{array}$ & 0.00401 & 0.00338 & 0.00431 & 0.00405 \\
\hline $\begin{array}{c}\text { Henan } \\
\text { Province* }\end{array}$ & 0.00412 & 0.00384 & 0.00427 & 0.00355 \\
\hline
\end{tabular}

\section{CONCLUSION}

The mortality decomposition model can capture the more information which has been missed by other models. And longevity risk index gives an explicit expression about longevity risk. Compared with the LRI, the modified LRI called MLRI is suitable for China. Our further steps are to finish its application for the portfolio correlated with longevity risk.

\section{ACKNOWLEDGMENT}

The paper was supported by two MOE projects of key research institute of humanities and social sciences in Universities (NO: 2011JJD790004 and 2009JJD790053). The work was finished under the support of "the program for Young Innovative Research Team of CUFE” (leader Pro. Zhang Liqing) .

\section{REFERENCES}

[1] Zhang Ning, Introduction and computation of longevity risk index based on mortality rate decomposition model, Springer Communications in Computer and Information, Volume 289, 2012, pp. 608-615 (2012)

[2] Pearlmutter, B. A. and Parra, L. C. Maximum likelihood blind source separation: A context-sensitive generalization of ICA. In Advances in Neural Information Processing Systems, volume 9, pp. 613-619 (1997)

[3] Emms, P. H. C. and Haberman, S. Income drawdown schemes for a defined contribution pension plan. Journal of Risk and Insurance, 75(3), pp. 739-761 (2008)

[4] Felipe, A., Guillen, M., and Perez-Marin, A. M. Rescent morality in Spanish population. British Actuarial Journal, 8, pp. 757-786 (2002)

[5] Lee, R.D. The Lee-Carter method for forecasting morality, with various extensions and applications. North American Actuarial Journal, 4(1), pp. 80-93 (2000)

[6] Lundstrom, H. and Qvist, J. Mortality forecasting and trend shifts: an application of the Lee-Carter Model to Swedish mortality data. Internaltional Statistical Review, 72, pp. 37-50 (2004)

[7] Olivieri, A. heterogeneity in survival models. Application to pension and life annuities. Belgian Actuarial Bulletin, 6, pp.23-29 (2006)

[8] Renshaw, A. E. and Haberman, S. On simulation -based approaches to risk measurement in mortality with specific reference to poisson Lee-Carter modelling. Insurance: Mathematics and Economics, 42, pp. 797-816 (2008)

[9] Wong-Fupuy, C. and Haberman, S. Projecting mortaltiy trends: recent developments in the United Kingdom and the United States. North American Actuarial Journal, 8, pp. 56-83 (2008) 